MANAGEMENT CONTROL OF PUBLIC AND

NOT-FOR-PROFIT ACTIVITIES

Geert Hofstede

Fasson Europe, Leyden, The Netherlands

RR-82-45

December 1982

Reprinted from Accounting, Organizations and Society, volume 6 number 3 (1981)

INTERNATIONAL INSTITUTE FOR APPLIED SYSTEMS ANALYSIS

Laxenburg, Austria 
Research Reports, which record research conducted at IIASA, are independently reviewed before publication. However, the views and opinions they express are not necessarily those of the Institute or the National Member Organizations that support it.

Reprinted with permission from Accounting, Organizations and Society 6(3):193-211.

Copyright $\odot 1981$ by Pergamon Press Ltd.

All rights reserved. No part of this publication may be reproduced or transmitted in any form or by any means, electronic or mechanical, including photocopy, recording, or any information storage or retrieval system, without permission in writing from the copyright holder. 


\section{FOREWORD}

In its program of research on management and technology issues, the International Institute for Applied Systems Analysis (IIASA) was concerned, inter alia, with comparative, cross-cultural studies of managerial attitudes and techniques. During 1979, when such studies were being pursued, Dr. Geert Hofstede was a leader in this work. It is with great pleasure, then, that we reproduce this article, which he wrote during the year he spent at IIASA.

ALEC M. LEE

Chairman

Management and Technology Area 


\title{
MANAGEMENT CONTROL OF PUBLIC AND NOT-FOR-PROFIT ACTIVITIES
}

\author{
GEERT HOFSTEDE
}

Fasson Europe, Leyden, The Netherlands

\begin{abstract}
Traditional approaches to management control usually fail for public and not-for-profit activities. ${ }^{1}$ The type of control applicable to such activities depends on four criteria: are objectives unambiguous, outputs measurable, effects of interventions known, and is the activity repetitive? Depending on where activities stand with regard to these criteria, the control applicable corresponds to one of six different types: routine, expert, trial-and-error, intuitive, judgemental, or political control. The first three types can be represented by cybernetic models; the other three ask for more complex and less deterministic models. For these, a "political" and a "garbage-can" model are described. Key elements in the latter models are the values and the culture of the actors. As an example, the typology for management control is applied to the area of budgeting, covering regular budgeting as well as such techniques as PPBS, MBO, and ZBB and distinguishing between investment budgets, operations budgets for input centers, and operations budgets for input-output centers. Coming back to management control in general, the paper discusses the consequences of choosing the wrong model for a given management control situation: it distinguishes between "Type I" and "Type II" errors. It finally relates management control to organizational adaptation and suggests how to avoid control systems which prevent an organizational system from learning.
\end{abstract}

There are no universally accepted definitions of the words "management" and "control", but the connotation of "management control" is a pragmatic concern for results, obtained through people. One definition by an authoritative U.S. author is that "management control is the process by which managers assure that resources are obtained and used effectively and efficiently in the accomplishment of the organization's objectives" (Anthony, 1965, p. 17). Management control in this sense is one of the main tasks of most managers - a task in which they are usually assisted by some formal control systems (such as budgeting and performance appraisal).

In the Western European and U.S. literatures, it is customary to speak of "management control" primarily in the context of the private (or at least independently functioning), profit-oriented organization. In Eastern Europe, the equivalent concept is "applied cybernetics", and the applications are primarily sought in production organizations. It is much rarer to find the "management control" concept applied to public or voluntary not-for-profit organizations in the West, and to non-production activities in the East. Yet an increasing part of the national resources both in East and West are spent on these latter types of activities. Even within the production and/or private sector, there is a shift from directly productive activities (to which the management control concept is most readily applicable) to "indirect" activities: those that bear no immediate

*This paper was written while the author was a visiting scientist at the International Institute for Applied Systems Analysis (IIASA), Laxenburg Castle, Austria. The author gratefully acknowledges his inspiration by the participants of a workshop on the subject, held in April 1979 at the European Institute for Advanced Studies in Management, Brussels, Belgium, in particular by Mark Cantley of IIASA. He also acknowledges the helpful comments on an earlier version of this paper by Arend Hulshof.

${ }^{1}$ I prefer using the terms "for-profit" and "not-for-profit" organizations and activities rather than the usual "profit" and "nonprofit" to stress the intent of making a profit or not; quite a few for-profit organizations, unfortunately, turn out to be nonprofit. 
proportional relation to outputs.

Because of the obvious need for people in command to control activities, even if these be public, not-for-profit, or indirect, it is desirable to expand the management control concept to such activities as well. However, this cannot be achieved by simple extrapolation from profit-oriented and production activities. The specific value of public, not-for-profit and indirect activities must be taken into account. In the following pages I shall first classify the wide range of these activities according to the forms of management control most readily applicable to them; from this, I shall arrive at a typology of management control approaches.

\section{CLASSIFYING ACTIVITIES FROM A CONTROL VIEWPOINT}

The title of this article runs "Management Control of ... Activities" rather than of "Organizations". It is more customary to relate forms of control to types of organizations, such as private, public or voluntary organizations, or productions, sales and service organizations. However, within each organization we find a range of activities which demand quite different forms of control. I referred already to "indirect" activities in production or private organizations; these cannot be controlled in the same way as "direct" activities. But in many public and not-for-profit organizations, we can still find activities that are "direct", in the sense of producing quite measurable outputs; these can be controlled in exactly the same way as direct activities in production organizations. Thus, for a meaningful classification from a management control viewpoint, we have to break our organizations down to the level of activities.

Measurability of outputs, as referred to above, is only one aspect of activities that determines the way in which they can or cannot be controlled. In fact, when classifying activities from a control viewpoint, we have to take four criteria into account:

(1) Are the objectives of the activity unambiguous or ambiguous?

(2) Are its outputs measurable or nonmeasurable?
(3) Are effects of management interventions in it known or unknown?

(4) Is the activity repetitive or nonrepetitive? ${ }^{2}$

Each of these four criteria will be discussed below.

Are the objectives unambiguous or ambiguous?

This is the most crucial criterion for management control. Control presupposes a target; what if there is no clear target? There are several reasons why objectives may be ambiguous:

(a) Because of conflicts of perceived interests and/or values among those having a say in the activity. For example, in running a prison, the director may be guided primarily by a desire for maximum security in protecting society, the psychiatric staff by maximum opportunities for rehabilitation of inmates, and the higher authorities by minimal cost. Voluntary, charitable or professional organizations are frequently the scene of value conflicts over objectives. The special ideological commitment of the members to such organizations make them assume the right and even the obligation to have their say in objectives; and one member's view are likely to differ from another's (Selby, 1978).

(b) Because of lack of knowledge about means-ends relationships in which the activity considered represents the means. For example, there may be agreement on a higher level objective such as "reduce unemployment" but different beliefs about whether the proposed activity will, in fact, reduce unemployment, leave it unaffected, or increase it.

(c) Because of fast changes in the environment ("environmental turbulence", see Emery \& Trist, 1969) which enforce new objectives or make existing objectives obsolete, without immediately suggesting new ones. For example, new legislation that enforces a tax on pollution, or new drugs that completely change the role of hospitals in treating certain diseases, may call for new objectives; but at the same time, many forces within organizations and within their environments push for a continuation of the old objectives.

Unambiguous objectives exist for activities for which there are no conflicts of interests and/or

\footnotetext{
${ }^{2}$ In an earlier publication (Hofstede, 1978) I discussed criteria 1, 2 and 4. Thompson (1967, p. 134) classifies control decision processes by criteria 1 and 3 ("certainty vs. uncertainty about preferences regarding possible outcomes", and "beliefs about cause/effect relations certain vs. uncertain").
} 
values among those concerned. These are all activities that form part of commonly accepted role patterns: such as those belonging to the role of a fireman, a stewardess, or a computer repairman. More generally, unambiguous activities exist where there is a consensus among organization members with regard to the activity, based on a shared tradition, shared indifference, or an unquestioning acceptance of a central authority that sets the objectives. They also exist where, regardless of members' values, a central authority or dominant coalition has a sufficiently strong power position to impose objectives.

\section{Are the outputs measurable or non-measurable?}

Management control presupposes that the output of an activity can be identified and compared to the targets that were set, and that this information can be used to redirect efforts within the activity where necessary. "Measurable" in this context really means "quantifiable", with as a marginal case of "quantification" the question whether a planned event did or did not take place (a 1 or 0 quantification). However, many activities both in private and in public organizations have outputs that can only be defined in qualitative and vague terms. How does one quantify the output of an army in times of peace? Of a public relations department? Of many management and staff activities? Of a ministry of eduction? In such cases only the inputs (the resources allocated to the activity) can be measured but not the outputs.

Some organizational experts hold that anything can be quantified and that the problem is merely to find the right measurement. I shall deal with this argument, which I believe to be a fallacy, later on in this article when discussing PPBS.

\section{Are effects of management interventions known or unknown?}

Effective management control presupposes that efforts allocated to an activity can be redirected if the outcome does not meet the set targets. However, this implies that the manager knows how to intervene in order to obtain the desired correction: the relationships between his intervention and the reaction of the organization, and between the reaction of the organization and the response of the environment, must be clear. The "technology" of the activity (in the widest sense) must be understood. Unfortunately this is often not the case. For example, one common intervention when outcomes are judged unsatis- factory is the replacement of key personnel - say of a project manager. Now it is not at all certain that this will indeed correct the deviation, and even if outcomes improve after the personnel change this may not be the effect of that change; it could be a delayed result of initiatives taken by the previous project manager, when the process has a natural time lag which higher management did not recognize. Most policy decisions are taken about activities for which the technology is at best only partly understood. Education is another field of ill-understood technology: relationships between interventions by educational authorities and their outcomes on what is learned by students are almost never clear. There is an irreducible uncertainty in most policy decisions, which cannot be quantified into a risk percentage (decisions for which risk can be quantified can be treated as "effects of management interventions known").

\section{Is the activity repetitive or non-repetitive?}

Repetitive activities (those that occur daily, weekly, a few times a year, once a year) allow a learning effect to take place which considerably facilitates control. This applies not only to purely cyclical activities, but also to changing configurations of repetitive elements, such as are found not only in industrial maintenance jobs but also in many professional activities: those of a doctor, a dentist, a social caseworker. Budgeting for current operations is an example of a repetitive process. Budget systems never function well the first year they are started, but after four or five cycles they may start to function well. Non-repetitive activities are unique programs, investments or campaigns. Because the activity in its present form will not come back, there is no learning effect: at the end of the program one may know how it should have been done, but this is of little help to anyone.

We have now discussed the four criteria for classifying activities. The next step is to combine these criteria and to identify the types of management control that go with each combination.

\section{A TYPOLOGY FOR MANAGEMENT CONTROL}

It will be immediately clear that management control is easiest if the four criteria mentioned 
above all satisfy the first alternative mentioned:

(1) objectives are unambiguous;

(2) outputs are measurable;

(3) effects of interventions are known;

(4) the activity is repetitive.

When one or more of the criteria does not satisfy the first alternative mentioned, the situation becomes more complicated. Figure 1 contains a typology in the form of a decision tree, which can be used to determine the type of management control likely to occur in this case: six types of management control have been distinguished.
It applies to most current operations in production and service organizations. This type of control can be prescribed in precise rules and regulations, can often be carried out by operative personnel themselves, and can sometimes be programmed into a computer.

\section{Expert control}

If objectives are unambiguous, outputs measurable, effects of interventions known but the activity is not repetitive (such as a one-off building project or the introduction of a new computer system), it makes sense to entrust control to

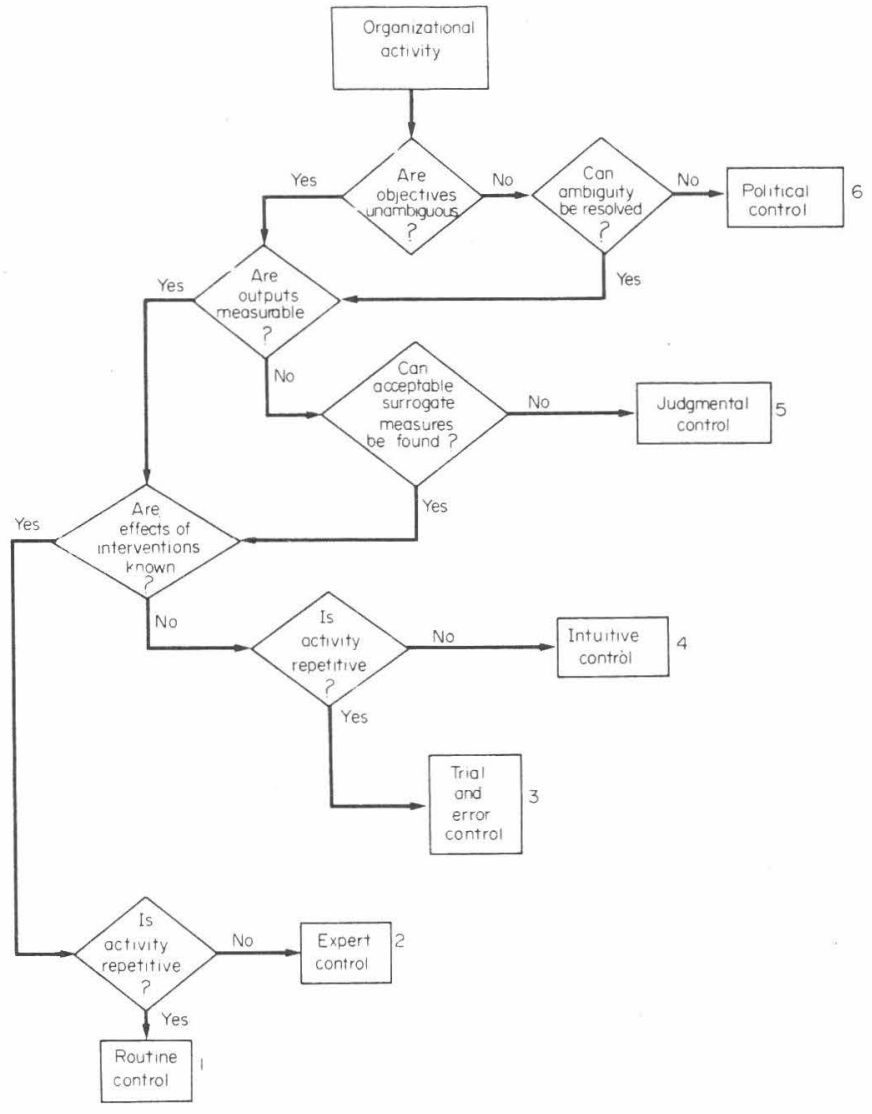

Fig. 1. A typology for management control.

\section{Routine control}

This is the easiest case which has just been mentioned: unambiguous objectives, measurable outputs, known effects of interventions, repetitive. someone for whom such activities are repetitive, that is, who has been able to learn about them on previous uccasions; such a person is an expert. The obvious danger of expert control is that the expert 
does not use the knowledge of effects of interventions already present among others in the organization: successful expert control depends on the integration of expert knowledge with support from those responsible for current operations.

\section{Trial-and-error control}

If objectives are unambiguous, outputs measurable, but effects of interventions not known, while, however, the activity is repetitive, the organization can learn to control through its own failures. Rigid rules and prescriptions are not possible but a thorough ex-post analysis of both successes and failures is called for. Examples are the introduction of new products, services or treatments; and the budget cycle for current operations.

\section{Intuitive control}

If, in the previous case, the activity is not repetitive, learning by trial and error cannot take place. In this case the organization has to rely on management control as an art rather than as a science, and find a person or persons who can be trusted to intuitively find the proper form of intervention needed to achieve the desired results. An example of this is the process of leading a demoralized football club or enterprise back to success (in these cases, the leader is usually given no time for trial-and-error cycles!). A special case of intuitive control is the process by which resources are obtained for new activities. In larger organizations, this is usually through proposals developed at lower levels which will then be approved or refused by higher levels. Each proposal is a non-repetitive activity; getting it accepted is a process in which the effects of interventions are unpredicatable. Bower (1970), after an extensive study of the resource allocation process in a large U.S. business firm, recommends a system of reviews by higher management of successive phases of the development of proposals. In fact, he recommends that the activity should be made repetitive, so that (in my terminology) intuitive control by those who try to get a proposal accepted is replaced by trial-and-error control. ${ }^{3}$

\section{Judgmental control}

We now have the case where outputs are not measurable even though objectives are unambiguous. In these circumstances, the first question to be asked is, whether any indirect measures of outputs can be found which can be considered acceptable "surrogates" or "proxies" for the missing direct measures (Anthony \& Herzlinger, 1975: 141). ${ }^{4}$ For example, Hulshof (1979) reports on control in a Dutch social welfare organization. The non-measurable output is the contribution of the organization to the well-being of the entire target population. Feasible indirect measures are the number of clients served and the average time spent per client. This is only meaningful, however, if clients can be divided into categories according to the time needed to reach a professionally acceptable level of help. If surrogate measures can be found that make sense and are acceptable to the parties involved, the control problem has become similar to the case of measurable output. If no indirect measures are available, control of the activity becomes a matter of subjective judgment; I have called it judgmental control. It depends on the power and influence structure of the organization whether there is one supreme judge (or coalition of judges) whose judgment is the basis for intervention; whether judgments have to be negotiated before intervention becomes possible, or whether no judgment is possible so that control happens only by accident or not at all.

\section{Political control}

From a control point of view, the most difficult case is when objectives are ambiguous. Above, I suggested three reasons for such ambiguity: (1) conflicts of perceived interests and/or values; (2) lack of knowledge about means-ends relationships, and (3) environmental turbulence. Organizations have ways, however, to resolve ambiguities so that external uncertainties become internal certainties and the control process can proceed in one of the ways described above. One way to resolve ambiguities is by the use of hierarchy: higher authorities or bureaucracies set the objectives which then, for those lower in the

\footnotetext{
${ }^{3}$ The four types of control described so far show some similarity with four alternative unit structures described by Shull et al. (1970, p. 84): routine, engineered, craft and heuristic task group structure.

${ }^{4}$ Sayles $(1972$, p. 30$)$ refers to the "tendency for easily quantified measures to drive out more subjective ones" - this is a Gresham's Law of output measurement.
} 
hierarchy, become unambiguous. Another way is by the use of rules and fixed policies; these represent basically arbitrary choices but they create a quasi-unambiguous setting. A third method which is often used when there are conflicts of perceived interests and/or values is that of negotiation; the negotiated settlement becomes the unambiguous objective. A fourth method involves the use of experts, especially in cases of lack of knowledge about means-ends relationships. The crucial factor in this latter case is the perception of the expert by the organization's managers: not whether he really knows, but whether he is credible to the organization as someone who can resolve ambiguity. A fifth way is control by crisis: letting a crisis situation develop in which the organization comes under exceptional stress. In such circumstances stress tends to reduce the number of alternative solutions which people can perceive and this reduction of perceived alternatives may make an ambiguous situation look unambiguous. Thus, the 1973-1974 oil crisis in the U.S.A. forced a decision about the Alaska oil project which had been delayed because of the conflict between environmental conservation and energy demand objectives (Slovic, 1978, p. 109). When ambiguities in objectives exist, control is always political control, dependent on power structures, negotiation processes, the need for the distribution of scarce resources, particular interests and conflicting values; however, political control at the top of an organization can go together with other forms of control inside the organization, because for the members, the political top may have resolved the ambiguities.

The model introduced in Fig. 1 applies to all types of organizational activities, whether the organization be private, public, for-profit or not-for-profit. It also applies to activities at all hierarchical levels, although there is a tendency for control Types 1 and 2 to occur at the lower and control Types 5 and 6 at the higher levels of organizations, with 3 and 4 lying in between.

Anthony (1965) has defined a framework for the analysis of planning and control systems in general, in which "management control" is only the second of three types which are related to levels in the hierarchy:

(1) Strategic planning: the process of deciding on objectives of the organization, on changes in those objectives, on the resources used to attain these objectives, and on the policies that are to govern the acquisition, use, and disposition of these resources.

(2) Management control: the process by which managers assure that resources are obtained and used effectively and efficiently in the accomplishment of the organization's objectives.

(3) Operational control: the process of assuring that specific tasks are carried out effectively and efficiently.

The typology of Fig. 1 includes all three of Anthony's types. However, most of "strategic planning" belongs by definition to control Type 6: political control. Political control is rarely discussed in management control theory. Most of "operational control" belongs to control Type 1: routine control. Only Anthony's "management control" may belong to all six types of control outlined in Fig. 1.

The typology of Fig. 1 need not be limited to activities taking place within one single organization; it can be applied to activities involving several organizations ("inter-organizational networks"). However, there will be a tendency in such activities for control to be mostly of Types 6 and 5: political and judgmental, because when several organizations are involved, conflicts of objectives are almost unavoidable, and outputs tend to be too complex to be measurable.

\section{CYBERNETIC MODELS OF MANAGEMENT CONTROL}

The dominant model for a control process is the first-order negative feedback loop; the dominant analogy is a thermostat. From this perspective, objective setting is analogous to the setting of the temperature. Measuring output corresponds with measuring actual temperature. Comparing output to objectives is analogous to comparing actual to set temperature. Feeding back unwanted variances to management is analogous to the negative feedback signal in the thermostat cycle. Finally, corrective intervention in the process is analogous to intervention in the flow of heat to the system. The dominant "thermostat" model can be extended in order to cover more complex organizational control situations. One possible extension is the addition of a feedforward loop using external information for a first 
anticipatory intervention in the process (Cantley, 1978, p. 28), with that intervention always being followed up by a feedback loop. A second possible extension of the "thermostat" model is the addition of second- and higher-order feedback loops that control the objective setting of the lower-order feedback loops, and possibly may over-rule the interventions of the first order loop (Hofstede, 1967, p. 100). All these are cybernetic models (Hofstede, 1978).

The cybernetic model really only applies fully in the case of routine control: Type 1 in Fig. 1. It applies marginally to Type 2 (expert control) and Type 3 (trial-and-error control): to Type 2 to the extent that the "expert" is supposed to have become expert through feedback from previous experience; to Type 3 if we accept that the model includes heuristic elements. However, it definitely does not apply when objectives are ambiguous (Type 6), outputs are not measurable (Type 5) or the effects of a once and for all intervention unknown (Type 4). ${ }^{5}$

Pure Type 1, routine control can be highly formalized, sometimes even quantified and computerized. However, even routine control processes usually involve communication between and motivation of people which means they contain a psychological element (Hofstede, 1976; Flamholtz, 1979). We can say that as soon as people are part of the process, the effects of interventions are no longer completely known; in Fig. 1, our routine control tends to become trial-and-error control because learning about human behavior usually takes place through trial and error. The cybernetic model now becomes complicated by psychological short-circuiting. In an earlier, empirical study of budgeting processes (Hofstede, 1967, p. 96) I have shown four such psychological short-circuiting possibilities: (1) people change the objectives rather than the process itself; (2) people change the measurements rather than the process itself; (3) people make the intended interventions but at the same time, they make some unintended interventions as well (such as, they adjust cost at the expense of quality); (4) people withdraw from the system by absenteeism (this means striking individually), striking collectively, or quitting. From these, 1, 2 and 3 are psychological short-circuits through which control changes into pseudo-control: this is a state in which the control system shows an equilibrium without the process actually being controlled.

The more formalized a control system, the greater the risk of obtaining pseudo-control rather than control; at least as long as there are people left in the process whose effort codetermines the outcomes. Pseudo-control can be avoided by eliminating the psychological rewards for it: by rewarding the interest in the process itself, and not in the measurements (Todd, 1977). One of the most promising ways for avoiding pseudo-control is moving control downward to the level of those who actually intervene in the process. This is contrary to F.W. Taylor's principle of the separation of control and execution. It replaces external control by self-control. in which the whole cybernetic cycle of measuring, comparing to standard, feeding information back, and intervening is in the hands of the same person or work group. This control cycle is linked to the surrounding organization only through the standards that are set. We can call such a process "homeostatic" rather than "cybernetic"; its analogy is not a thermostat but a biological element represented by a living cell. The cell is equipped with internal processes capable of maintaining an equilibrium in a changing environment, provided that environmental conditions do not become too unfavorable (Hofstede, 1978; den Hertog, 1978). Avoiding pseudo-control through self-control can be seen as an application of Ashby's Law of Requisite Variety (Ashby, 1956, Ch.11). As a major source of variety in the outcomes is in the people who execute the process, only these people themselves possess the control variety that can regulate the process.

The cybernetic model of management control is a special case of the "Cycle of Organizational Choice" as pictured by March \& Olsen (1976). This is reproduced in Fig. 2.

If we apply the model of Fig. 2 to the control situation, the objective or standard is represented by box A, people's preferences or "models of the world". In control situations, these preferences tend to be controlled by a higher-order circuit (the standard setting process). Arrow $a$ represents the measurement process. In box $\mathrm{A}$, measures are also checked against preferences. Arrow $b$ represents the feedback signal. Box B is its reception and

\footnotetext{
${ }^{5}$ Weick (1974) criticizes a number of assumptions that are made when organizations are pictured as (open) systems and warns explicitly against the cybernetic model: "be suspicious of thermostats".
} 


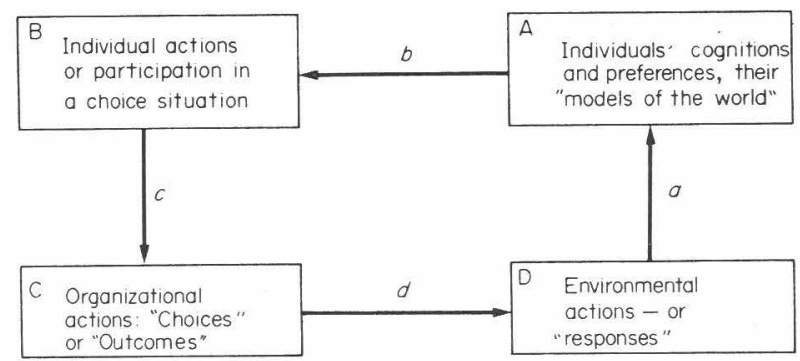

Fig. 2. The complete cycle of organizational choice (March \& Olsen, 1976, p. 13).

translation by individual actors. Arrow $c$ is the intervention in the organizational process; the latter is represented by box C. Arrow $d$ represents the technology of the process, box $D$ its translation into outputs.

March and Olsen use their "Cycle of Organizational Choice" to argue that in many cases, one or more of the arrows are interrupted. This also happens in the control situation; and in these cases the cybernetic model can no longer be used. If the arrows are intact, we are dealing with the control types 1, 2 and 3 in Fig. 1. If one or more are interrupted, we deal with one of the other types. Unfortunately, the cybernetic model is so attractive and has been so successful where it does apply, that it is frequently used beyond its zone of applicability, because the assumptions that have gone into it are not realized (Anthony, 1965, p. 87; Hofstede, 1978). In the next section, we shall look at non-cybernetic alternatives which do apply when one or more of March and Olsen's arrows are interrupted.

\section{NON-CYBERNETIC "MODELS"}

The pure cybernetic model assumes rationality of the entire system. For Anthony (1965, p. 93), the source disciplines of routine control (which he calls "operational control") are economics and the physical sciences. Admitting psychological elements into the system (Type 3 control), the system is no longer fully rational; for Anthony, the source discipline of management control is social psychology.

Two types of alternative "models" are available for control Types 4 and especially 5 and 6 in Fig. 1: political control and "garbage-can" control.

The political control model assumes that there are several actors in the system who each act subjectively rationally: they act in their own perceived self-interest, but the consolidated result of their actions does not represent a rational total system. In some such models it is acknowledged that the behavior of the actors might be able to be predicted by the use of some theoretic concepts. We find elements of such a political model, implicitly rather than explicitly, in, for example, Crozier's (1964, p. 117) description of power games in the French tobacco monopoly, and in Anthony \& Herzlinger's (1975, p. 249) description of twenty-eight "ploys" to be used in budget negotiations, and how to counter them.

The "garbage-can model" was outlined by March \& Olsen (1976) for the cases in which the "cycle of organization choice" does not function (see Fig. 2: we considered this cycle as a more general form of the cybernetic model). Each of the arrows in the cycle can in practice be interrupted (March \& Olsen, pp. 56-59). If arrow $a$ is interrupted (Fig. 2), this corresponds to our case of non-measurable outputs (Fig. 1). If arrow $c$ and/or $d$ are interrupted, this corresponds to a case of unknown effects of interventions. If arrow $b$ is interrupted, individual action is not affected by knowledge coming through the system; individuals do not react to the feedback signals received, for example because they are complying with standard operating procedures. ${ }^{6}$

\footnotetext{
${ }^{6}$ Birnberg et al. (1977) suggest the use of "attribution theory" to explain human behavior in control systems. Attribution theory deals with the question to which causes people attribute events; these attributions depend partly on the attributors, partly on the situation. Birnberg et al., expand the cybernetic model to reflect attribution processes. Attribution theory among other things explains why different people react differently to the same feedback signals.
} 
March and Olsen suggest for such cases a "garbage-can model of organizational choice" (based upon earlier work with M. D. Cohen). This model applies to organizational situations in which no assumptions are made about the existence of hierarchical structures or generally accepted rules; the authors call them "organized anarchies". Objectives may be ambiguous, outputs nonmeasurable, effects of interventions not known, activities non-repetitive. Even the participants in the choices may not be known in advance, and actually wander in and out. The authors illustrate their model with data from educational institutions (schools and universities) in the U.S.A. and Scandinavia. In the "garbage-can" process, all issues that confront the organization at a given time are put simultaneously into a "garbage-can", which poses a limit to the amount of attention available. There are more or less independent flows of problems, solutions, participants and choice opportunities in and out of the "garbage-can", and choices are not only made by resolving problems but also by overlooking them or deliberately escaping from them. This process is non-rational. It is not rational at the systems level, nor is it rational at the individual level, because self-interest is ambiguous: people often do not know what they want. The one leading principle of action in such ambiguous situations is that individuals look for cognitive consistency: they try to have models of the world that to them make some sense. In order to maintain this they are able to do non-rational things: to forget, to overlook, to play

A key element in both the political and the "garbage-can" model are the values of the actors. Values are broad preferences for one state of affairs over others which are relatively stable over time. In the political model, values determine how the actors perceive their self-interest: if we know their stable values, we can come closer to predicting their behavior. In the "garbage-can" model, values are the elements of the actors' "models of the world" and they determine what state of affairs to them will be cognitively consistent.

This means that if we want to analyse or improve control of the Types 5 and 6 in Fig. 1 (judgmental and political control), we should include the study of values in our program.?
Without the study of values, policy really corresponds to the definition which Stringer (1976, p. 23) cites from the Oxford English Dictionary: "a form of gambling in which bets are made on numbers to be drawn in a lottery". If, in these circumstances, we want to make better bets, we have to study values. Values are non-rational, however: they precede the use of rationality.

The "garbage-can" model, as opposed to the political model, also has room for rituals. Rituals are activities performed because of the subjective meaning they carry for those performing them. They are symbolic activities, essential elements in the cognitive consistency which the "garbage-can" model assumes people try to maintain. They are stress-relieving. We tend to accept defining activities as rituals in religious ceremonies, possibly even in social ceremonies, but the ritual element in work, business and government is rarely recognized. When the word "ritual" is applied to work activities, it tends to carry the connotation of "useless and ineffective". In fact, ritual activities, even at work, are neither useless nor ineffective; they are necessary and inescapable because we all have our needs for cognitive consistency. But there are good rituals and bad rituals. Good rituals support social cohesion and relieve stress because they concur with the values of the people concerned, and they have no negative consequences for the organization or any of its members. Bad rituals conflict with values or are damaging to people or organizational outputs.

Examples of ritual activities in work organizations are given in Hofstede (1977, p. 42): meetings, memos and reports, parts of accounting systems, parts of planning and control systems, often the use of experts. ${ }^{8}$ Together values and rituals are manifestations of the culture of human groups. Types 5 and 6 control through their values and ritual elements, are therefore strongly culturally dependent; and even other control types, through the role of people in them, carry a cultural component. (My own short definition of "culture" is: "the collective programming of the mind that distinguishes the members of one human group from another". The human groups in question can be nations, industries, organizations, occupations, social classes, age groups and others; control systems will reflect the culture of the

\footnotetext{
${ }^{7}$ Hammond \& Adelman (1978) propose a normative model of policy decision-making in which supposedly rational expert's judgments are weighed by politicians' value judgments.
}

${ }^{8}$ Stringer $(1976$, p. 35$)$ points to the ritual elements in employment and unemployment. 
organization they function in, and of the larger units the organization belongs to, such as industries and nations.)

It is unlikely that we shall succeed in imposing on organizations control systems that run completely counter to their organizational culture. Control reforms have got to be sensitive to organizational cultures. It is unlikely that we can transfer to a hospital or government office a control system developed in an automobile manufacturing company, even for similar problems: we have to adapt it to the mental programming dominant in those organizations (Hofstede; 1967, p. 291). Derlien (1978a) draws attention to the culture of secretiveness in public administration in Germany. Secretiveness is probably a fairly universal characteristic of the culture of public administrators, which will influence the rituals and procedures they need for cognitive consistency in judgmental and political control processes.

Also, we cannot indiscriminately export control systems from one country to another. In an extensive study of national cultures in forty countries (Hofstede, 1979, 1980b), I found among other things wide differences between countries in patterns of uncertainty avoidance (Hofstede, 1977). Nations differ in the extent to which their average citizens tolerate uncertainty about the future. For example, such tolerance is lower in France, Japan and Germany than in India, Great Britain and Sweden; the U.S.A. in this respect is very much in the middle. A lower average level of tolerance for uncertainty leads to a higher average level of anxiety (which can be demonstrated in medical symptoms). Higher anxiety leads to a greater need for anxiety-relieving, uncertaintyavoiding rituals. In the fields of judgmental and political control (Types 5 and 6), this leads to the adoption of more strictly formalized procedures, to a need for formal rules rather than unstructured negotiations. ${ }^{9}$ Thus, judgmental and political control take different forms in different countries and this should be so, for the deep-seated ritual needs to which these processes cater are not the same for all countries. There are no universally optimal procedures for judgmental and political control, while there are very likely universally optimal procedures for routine control.

Even with a profound knowledge of national and organizational cultures, value systems and ritual needs, political and especially garbage-can models of management control systems will lead to considerably less precise predictions of how control will work, than cybernetic models do. This explains the continued attractiveness of cybernetic models in control situations where they do not apply. However, I believe that a vague model that corresponds to reality is still preferable to a precise model that does not.

\section{AN APPLICATION TO THE AREA OF BUDGETING}

Budgets are a major vehicle for management control. Most activities in organizations consume financial resources; some also produce such resources. Money is usually the only common denominator for all activities in the organization, which makes the budget system that tries to control the flow of money into a focal part of the management control system.

From a management control point of view, three types of budgets should be distinguished (see Table 1):

1. Investment budgets: any attribution of resources to assets to be used for more than one budget period (the budget period is almost always one year),

2 and 3. Operations budgets for "input" centers, and operations budgets for "inputoutput" centers. Operations budgets are any attribution of resources to one budget period only. The distinction between "input" centers and "input-output" centers is more commonly known in the Western literature as the distinction between "expense centers" and "profit centers", but in the context of public and not-for-profit activities the word "profit" would be ill-chosen. The more fundamental distinction is that for some activity centers in organizations only the resources put into them can be expressed in money: the outputs are non-measurable (see above) whilst for others, both inputs and outputs can be given a monetary value.

The distinction between the three types of budgets in Table 1 has consequences for the types of management control (according to the typology of Fig. 1) that will be used, as shown in the second

${ }^{9}$ The relationship between anxiety, a need for rules, and a "Quest for Control" has earlier been recognized by Van Gunsteren (1976). 
TABLE 1. Types of budgets from a management control viewpoint

\begin{tabular}{|c|c|c|c|c|}
\hline Type of budgets & $\begin{array}{c}\text { Types of management } \\
\text { control involved } \\
\text { (Fig. 1) }\end{array}$ & $\begin{array}{c}\text { Major } \\
\text { management problem }\end{array}$ & $\begin{array}{c}\text { Available } \\
\text { tools/techniques }\end{array}$ & $\begin{array}{c}\text { Social } \\
\text { processes involved }\end{array}$ \\
\hline $\begin{array}{r}\text { Investment } \\
\text { budgets }\end{array}$ & $\begin{array}{l}\text { (2) Expert control } \\
\text { (4) Intuitive control } \\
\text { (5) Judgmental control } \\
\text { (6) Political control }\end{array}$ & $\begin{array}{l}\text { Resource } \\
\quad \text { allocation }\end{array}$ & $\begin{array}{l}\text { Economic analysis } \\
\text { DCF } \\
\text { PERT }\end{array}$ & $\begin{array}{l}\text { Discretionary power } \\
\text { Negotiation } \\
\text { Salesmanship }\end{array}$ \\
\hline $\begin{array}{l}\text { Operations } \\
\text { budgets for } \\
\text { input centers }\end{array}$ & (5) Judgmental control & $\begin{array}{l}\text { Resource } \\
\quad \text { allocation } \\
\quad \text { Plus } \\
\text { Performance } \\
\quad \text { motivation }\end{array}$ & $\begin{array}{l}\text { PPBS } \\
\text { MBO } \\
\text { ZBB } \\
\text { Policy analysis } \\
\text { Program evaluation }\end{array}$ & $\begin{array}{l}\text { Discretionary power } \\
\text { Negotiation } \\
\text { Salesmanship } \\
\quad \text { Plus } \\
\text { Leadership } \\
\text { Subordinateship } \\
\text { Motivation } \\
\text { Gamesmanship }\end{array}$ \\
\hline $\begin{array}{l}\text { Operations } \\
\text { budgets for } \\
\text { input -output } \\
\text { centers }\end{array}$ & $\begin{array}{l}\text { (1) Routine control } \\
\text { (3) Trial-and-error } \\
\text { control }\end{array}$ & $\begin{array}{l}\text { Performance } \\
\text { motivation }\end{array}$ & $\begin{array}{l}\text { Semi-participative } \\
\text { Budget setting and } \\
\text { Feedback of budget } \\
\text { Variances } \\
\text { MBO }\end{array}$ & $\begin{array}{l}\text { Leadership } \\
\text { Subordinateship } \\
\text { Motivation } \\
\text { Gamesmanship }\end{array}$ \\
\hline
\end{tabular}

column of Table 1 . Investment budgets are mostly non-repetitive, a characteristic which excludes control Types 1 and 3 in Fig. 1; however all other types of control may occur depending on whether the objectives of the investment are unambiguous or ambiguous, its outputs measurable or nonmeasurable, and the effects of interventions on the actual cost known or unknown. Operations budgets for input centers are by definition a case of non-measurable outputs, a characteristic which defines the type of control to be used as one of a judgmental nature, unless acceptable surrogate measures can be found, in which case the input center becomes an input-output center. Operations budgets for input-output centers, again by definition, represent a case of measurable outputs; in addition, however, they almost always deal with repetitive activities, so the appropriate types of control are routine (Type 1) or trial-and-error (Type 3).

The three types of budgets present different problems to management (that is, to those trying to use them for control purposes); they utilize different tools and techniques, and they lead to different kinds of social processes among the people involved (see Table 1, last three columns). In the following paragraphs we shall look at each of the three types in turn.

\section{Investment budgets}

For investment budgets, the major management problem is one of resource allocation: the choice between alternative applications of limited resources. The available management tools and techniques for investment budgeting treat it as an economic problem for which an optimal solution can be found by appropriate economic analyses. A basic element of most such techniques is Discounted Cash Flow: an accounting for the time value of money. Another technique recommended for investment planning (and subsequent control) is PERT (Program Evaluation Review Technique). However, the decisive role in resource allocation for investment budgets is often played not by economic considerations, but by social processes which the available techniques do not take into account. $^{10}$

The social processes involved in investment budgeting include (1) the wielding of discretionary power by those individuals or bodies whose hierarchical or statutory position makes them into decision-takers; this is political power; (2) processes of negotiation between members of decision-making bodies, their advisors, and other

\footnotetext{
${ }^{10}$ One study dealing with the organizational, non-economic aspects of investment budgets is that of Bower (1970); see earlier in the article.
} 
parties having stakes in the decision; this is political negotiation; and (3) salesmanship on the part of defendants of particular investments; this is political strategy, or guile. Economic analysis is often only used for contributing strategic arguments, as part of salesmanship, and for justifying choices that were predetermined by non-economic criteria in the first place (e.g. Aharoni, 1971). When seen in such terms, it is not so important that the economic arguments supporting an investment decision are right in an absolute sense; it is far more important that they appeal to the decision-makers. Moreover the correctness of the economic assumptions entering into investment proposals is rarely checked afterwards; and even if it is checked, nobody is likely to learn from any errors discovered, as the process is non-repetitive.

\section{Operations budgets for input/output centers}

When budgeting for both inputs and outputs the major management problem is performance motivation: coordinating the efforts of the people involved towards obtaining the best possible ratio of outputs over inputs. This is because inputs usually cannot be controlled by discretionary decisions of management: if inputs were to be stopped, outputs are disturbed and the net effect on the output-input ratio is the opposite of what was intended. A classical example (Hofstede, 1967, p. 23) is the sales office where all the salesmen were found to be sitting at their desks at the end of each month because their car expenses were not paid beyond the budget limit. In such a situation car expenses were definitely reduced, but sales and profits also dropped sharply.

The tools and techniques used for operations budgets for input-output centers are the classical budget control methods: the setting of goals expressed in money and the feeding back of the variances - the differences between goal and actual outcome - to those responsible for managing the operations. Many books cover the administrative side of these techniques (there are a number of versions available, each claiming superiority over the other versions). Studies of the organizational and human implications of these techniques are less common however (Hofstede, 1967; Dunbar, 1971). What studies are available show that with appropriate leadership, the techniques can be quite effective; however, that leadership is a more essential condition for success than any particular version of the technique, provided that gross administrative errors are avoided. Macro-influences like technology (Hofstede, 1967, p. 286ff), organizational structure (Bruns \& Waterhouse, 1975) and national culture (Aharoni, 1971, p. 38; Hofstede, 1977) also are known to play a role in the effectiveness of such techniques. In Table 1, I have called the budget-setting process needed in this case "semiparticipative": it should combine participative inputs from those having to fulfil the budget, with central coordination, to respect overall constraints (Hofstede, 1967, p. 173ff).

In order to reinforce the motivation of those having to fulfil the budget, financial incentives are sometimes used. The unavoidable arbitrariness of budgetary standards makes them poor bases for financial incentives, and in my earlier study I advised strongly against budget-variance based financial incentives (Hofstede, 1967, p. 257). Budget accomplishment can, however, be a sensible criterion with another motivational "technique", namely Management By Objectives (MBO). We shall meet MBO again below. I shall argue that psychologically, it only functions properly where results are measurable, which is the case for input-ouput centers. MBO in such cases, if applied with sufficient leadership skill, can be a useful motivational tool because it replaces the impersonal automatism of a financial incentive by a personalized but quantitatively supported evaluation. In fact, input-output centers may be the only places in which MBO really can work.

The social processes involved in operations budgeting for input-output centers, according to the above, are primarily leadership with its unavoidable mirror image; subordinateship because effective leadership consists in fulfilling the role demanded by the subordinateship that is part of the organizational and national culture (Hofstede, 1979). Leadership, subordinateship, the task at hand, the culturally determined needs of the organization members all contribute to a pattern of motivation - which may or may not help towards budget fulfilment. The most essential social process which forms the main theme of my earlier book (Hofstede, 1967) is gamesmanship Budgeting is always a game of strategy - this applies to all three types of budgets in Table 1. In input-output centers, it should also be seen as a game of skill: the motivation is optimal if all actors involved consider budgetary targets as worthwhile challenges whose attainment is highly 
desirable but whose non-attainment is an accepted risk.

\section{Operations budgets for input centers}

The middle type of budget in Table 1, the operations budget for input centers, is the most problematic case from a management viewpoint because it poses both kinds of problems: resource allocation plus performance motivation. Resource allocation, because the resources could, at least in theory, be attributed to alternative activities or not at all, without any immediate measurable effect on outputs. Performance motivation, because in order to fulfil the mission of the center, the efforts of the people involved have to be considered, even though the outputs are non-measurable: management control in this case consists of obtaining a performance of the center that is subjectively and qualitatively optimal, or at least satisfactory.

Operations budgets for input centers are the domain where techniques have most proliferated during the past two decades. Like the other techniques mentioned earlier, all of these originated in the U.S.A. which has always been a captive market for new organizational tools tools that are easily adopted but easily dropped as well. The best known technique in this area is Programming Planning Budgeting System (PPBS). It originated in the early 1960 s when Robert McNamara moved from the top management of the Ford Corporation to the position of Secretary of Defense. PPBS transfers the idea of "product management" from private business to public and not-for-profit activities. Product management, however, assumes a situation of measurable outputs: an input-output center. In transfering its philosophy to the not-for-profit sector, the protagonists of the system have rather lightly walked over the fact that (Fig. 1) many objectives here are ambiguous, and outputs non-measurable. They have assumed that by "trying harder", ambiguities could be resolved and acceptable surrogate measures for output could be found, thus replacing (Fig. 1) political and judgmental control by one of the simpler types. PPBS implied: (1) focussing on programs rather than on departments in planning and budgeting, which meant focussing on outputs rather than inputs and (2) taking into account a time horizon beyond the single year for which operations budgets are traditionally made. In fact, in Table 1 this means that the middle type of budget is "dissolved" by making it at the same time more like the lower type (focus on outputs) and like the upper type (more-than-one-year time horizon).

The impact of PPBS has been extensively documented (Anthony, 1972; Lyden \& Miller, 1972; Wildavsky, 1975, 1978a, 1978b; Jablonsky \& Dirsmith, 1978; Hofstede, 1978). It has mostly been considered a failure, because it has buried the fundamental political and judgmental choices in not-for-profit activities in "techniques" and paperwork, making its own cost-benefit balance negative. PPBS has been exported to other organizations and other countries on the basis of the first enthusiastic reports of those having a stake in introducing it; and by a curious process of inertia in the communication of experience, it was and still is introduced as the road to salvation in some organizations after it has long been abolished as a failure in others. A sober evaluation of PPBS is a statement from Derlien (1978b) about the results of PPBS-inspired reforms in the German Federal Bureaucracy: the reforms have represented a significant shift in the attitudes of bureaucrats. Measured by the expectations of the reformers, they have failed; measured by the much more modest expectations of the users, they have succeeded. ${ }^{11}$

Another technique applied at input centers for creating management control where the budget fails to do so is Management By Objectives (MBO) which we already met for use in input-output centers. In the U.S.A. MBO has been used on a massive scale as a control tool for such input centers as government offices and universities. Its achievements are very modest, however; it seems to work (and still only under certain leadership/ subordinateship conditions) where results are unambiguously measurable, that is in inputoutput centers (Ivancevich, 1974; Hofstede, 1978; Dirsmith \& Jablonsky, 1979). In input centers, $\mathrm{MBO}$ tends to fail for two reasons: (1) it is based on naive assumptions on the psychological processes between superiors and subordinates who will not agree on the evaluation of results, even if they agreed earlier on the formulation of objectives and (2) the separation of objectives from resources and constraints is a semantic exercise which has little to do with the reality of

\footnotetext{
${ }^{11} \mathrm{~A}$ rather similar statement was made on the basis of research in PPBS-inspired reforms in the Belgian Ministry of French-language Education, in a paper presented at the EIASM-IIASA workshop by Luc Wilkin (as yet unpublished).
} 
organizational life. Wildavsky (1978a, p. 79) states:

.. objectives by themselves are meaningless: they suggest that everything may be obtained and nothing need be given up. Objectives make sense only in the context of resources available to achieve them together with an understanding of alternatives foregone. Yet considering opportunity cost immediately suggests a full-scale analysis, which, presumably, MBO is designed to avoid.

A third technique developed specifically for input centers, is Zero Base Budgeting (ZBB). ZBB has also originated in U.S. private industry (at Texas Instruments) and was transferred to the U.S. public sector in the early 1960s. The idea is that the budget for input centers is split by activities, and that for each activity, various levels of expense with their expected consequences are considered, including a zero level. Subsequently, decision makers rank the activities in order of desirability, and the actually available level of resources determines the cutoff point beyond which activities will not be funded. This may then lead to some activities being discontinued altogether, others reduced, while still others are expanded at the same time. The documentation on $\mathrm{ZBB}$ is extensive (e.g., Anthony \& Herzlinger, 1975, p. 245; Wildavsky, 1975, 1978a, 1978b; Cheek, 1977; Bariff \& Galbraith, 1978; Sarant, 1978; Wholey, 1978; Draper \& Pitsvada, 1979; Herzlinger, 1979). It was strongly promoted by Governor Jimmy Carter of the State of Georgia, and again (but somewhat less strongly) by him in the U.S. Federal Government after his election to the Presidency. All in all, reports on its effects are not optimistic (Wildavsky, 1975, p. 278: "Some butterflies were caught, no elephants stopped"). The reasons for this are that (1) decision packages for which decision makers have to set priorities soon become unwieldy in size so that informed decisions can no more be taken; the paperwork becomes extremely costly, its costs far exceeding the potential benefits and (2) like PPBS and MBO, $\mathrm{ZBB}$ is based on naive assumptions about human reactions to the system and about people's political behavior and psychological impact on each other. It is extremely unlikely that managers will submit ZBB budget proposals that would, if accepted, put them out of their own job: they make use of many political "ploys" to avoid such proposals, or to make absolutely sure that they will not be accepted. Beneficial aspects of a ZBB approach can only be expected given a number of restrictions: (1) a much simplified version, in which the request is not to consider reduction of activities to zero, but to consider the effect of marginal reductions or additions of budget (say, $\pm 15 \%$ ) and (2) appropriate decentralization so that decisions would be taken on relatively small packages of alternatives by people sufficiently close to the activities to be familiar with their details. In this case, ZBB is mainly a technique for stimulating trade-offs between budget items, alleviating the rigidity of itemized budgets in which money can only be used for items specified; itemization is a common feature of public and private sector budgets which leads to overspending and demotivation (Aharoni, 1971).

The alternatives to the pre-packaged techniques mentioned (PPBS, MBO, ZBB) in the case of input centers are forms of Policy Analysis and Program Evaluation (Wildavsky, 1972, 1978a; Abt, 1976): audits of activities by, usually, special teams including all their impacts: financial, political and psychological. This is no easy solution either. Having such audits represents in itself a political choice, and decision makers will always be tempted to reject their results. Analysts and evaluators bring their own biases to their audits (Van de Vall \& Bolas, 1977). Policy Analysis and Program Evaluation, however, at least do not suggest simplistic ways of dealing with complex problems, and they do not contain built-in naive assumptions nor built-in mountains of paperwork.

The social processes in operations budgeting for input centers are very complex, as they combine those described for investment budgets with those described for operations budgets for input-output centers. For those working under such a system, both salesmanship and gamesmanship are at a premium, but the games played tend to be games of strategy (political games) rather than games of skill (performance motivation). The role of leadership in this case is, taking account of the type of subordinateship prevailing, to turn the game as far as possible into a game of skill.

\section{THE CHOICE OF MODELS: TYPE I AND TYPE II ERRORS}

The argument in the previous sections can be summed up as follows: there are two main categories of management control situations. The first are the relatively routine, mechanistic situations, corresponding to Type 1 (and marginally Types 2 and 3 ) in Fig. 1. For this 
category, a cybernetic model is appropriate. These situations are not too dependent on the actors' values (although human behavior does play a role in them and pseudo-control is a danger) and for managing them, the well known traditional management principles (technical, economical, psychological) apply. The second category are the non-routine, ill-defined, ill-structured situations, corresponding to Type 4 and especially Types 5 and 6 in Fig. 1. For this category, the cybernetic model emphatically does not apply and it may lead to a dangerous covering-up of the real issues which are of a "political" nature, largely determined by values and rituals. For this category, only vague "models" exist: I mentioned a political one and a "garbage-can" one.

The practical conclusion to be drawn from this dichotomy is that before we use a model (or we could call it a paradigm) to describe or analyse a management control situation, we should first carefully study the nature of that situation which determines which model or paradigm is appropriate. This is why in the beginning of this paper I stressed looking at activities rather than organizations: different models may apply to different activities within the same organizations.

There are, in fact, two types of errors we can make. These are analogous to the "Type I" and "Type II" errors in statistical hypothesis testing. A Type I error means rejecting a true hypothesis; a Type II error accepting a false hypothesis. In our case, a Type I error means not using a cybernetic approach where the situation meets the conditions for it. A Type II error means attempting to use a cybernetic approach where the situation does not meet the conditions for it (Landau \& Stout, 1979. ${ }^{12}$ )

Type I errors are quite frequent in nonproduction public and not-for-profit organizations (Anthony, 1972, p. 23), because in their organizational subcultures the concern for cost and effectiveness has traditionally been missing. Hulshof's (1979) paper is an illustrative case (see above). The control problem is the allocation of resources to a Dutch Social Welfare organization, which so far has been entirely judgmental. The subculture of the organization is one of professionalism and a resistance to thinking in terms of "efficiency" when dealing with the clients.
However, a growing incompatibility between (1) the number of clients, (2) the amount of time the professionals think they should spend on each client and (3) the short and long-term availability of resources forces the organization to engage in some kind of conscious priority-setting which is a form of performance control within the constraints set by available resources. Hulshof shows that because the activities are highly repetitive, statistical data can be collected on time devoted to cases. For these to be meaningful, however, professionals have to design some classification of cases, which they tend to resist. The repetitiveness of the process makes it likely that a classification is possible which can be used as the basis for an acceptable surrogate output measure; with this, the type of control becomes No. 3 in Fig. 1: trial-and-error control, to which a cybernetic philosophy does apply. The main problem in this case is one of implementation: to overcome the traditional resistance of these professionals to efficiency thinking where such thinking can be beneficial to all. More generally, situations in which Type I errors can be expected are all repetitive activities in non-production, public and not-forprofit organizations; the more routine the activity, the more applicable is the cybernetic paradigm.

Whereas Type I errors in non-production, public and not-for-profit organizations tend to be many but each of them relatively small, involving only a limited part of the organization, Type II errors tend to be few but large. Type II errors are made when large-scale, sweeping techniques are introduced to improve management control processes of the judgmental and political type, programs which at closer scrutiny use a cybernetic paradigm.

Time and again, control systems, imposed in the name of error prevention, result only in the elimination of search procedures, the curtailment of the freedom to analyse, and a general inability to detect and correct error (Landau \& Stout, 1979 , p. $26 .{ }^{13}$ )

As examples of such Type II error cases we saw the introduction of Planning-ProgrammingBudgeting (PPBS); Management by Objectives $(\mathrm{MBO})$; and Zero-Base Budgeting (ZBB). Under certain conditions, $\mathrm{MBO}$ and a simplified form of ZBB may work; but a sweeping introduction without regard for those conditions is a Type II error.

\footnotetext{
${ }^{12}$ In my own management control teaching, I have used the Type I-Type II error distinction before I received the Landau and Stout paper; we have come independently to the same analogy.
}

${ }^{13}$ Extensive analysis of Type II errors are found in Wildavsky (1975) and Van Gunsteren (1976). 


\section{CONTROL AND ORGANIZATIONAL ADAPTATION}

Cybernetic control systems, paradoxically, are systems that do not learn. By keeping the activity on target, they prevent it from learning. The control processes that allow the organization to learn are the non-cybernetic ones, the judgmental and the political. In a changing world with a turbulent environment (Emery \& Trist, 1969), the adaptation and therefore the long-term survival of the organization depends upon the effectiveness of these processes; the aim being not to keep the activity on target, but to choose the appropriate targets at the appropriate time. The larger and more complex an organization or organizational network, the greater its inertia. We saw above that standard operating procedures sometimes prevent individuals from reacting to feedback signals. This tendency is much stronger at the organizational or inter-organizational level and leads to "dynamic conservatism" (Schon, 1971, p. 31ff): fighting like mad to stay the same. ${ }^{14}$

Ecologists have studied the properties of species to survive under dramatically changing circumstances. The key to such survival is not equilibrium, but a property which has been called resilience (Holling, 1973; Vayda \& McCay, 1975): near-synonyms are ultrastability, homeostasis, coping, adaptivity, robustness. Resilient systems have been modelled as regular first-order cybernetic feedback cycles with a second-order loop superimposed on it, which periodically adjusts the standards of the first-order cycle if the survival of the organism under the changed environmental conditions asks for it; however this second-order loop has standards that are judgmental or politically determined. This higher-order cybernetic "model" has for example been described by Ashby (1965, pp. 7-26) and applied to organizational situations by Cantley (1973) and Argyris (1977): the latter speaks of "double-loop learning".

The worrying question is: in view of the predominant tendency of individuals and organiza- tions to move to "standard operating procedures" (which is single loop learning), who will teach organizations double-loop tricks? The traditions, dominant values, and political systems of countries and organizations constrain the options available to managers in this respect (Hofstede, 1979) and they are reflected in the recommendations found in the literature.

From the U.S.A., Argyris (1977) assumes the possibility of a conversion to double-loop learning of the organizations' top decision-makers. March has developed his "garbage-can" model based on U.S. experiences, ${ }^{15}$ in combination with Scandinavian examples. The idea of "semi-confusing" information systems to destabilize standard operating procedures comes from Sweden (Hedberg \& Jönsson, 1978). In a case study of a large Dutch corporation (Hofstede, 1980) I suggest another institutional solution to double-loop learning: the appointment of a person in a "court jester" role, whose task it is to collect the weak and suppressed signals from the environment and have direct access to the top decision-makers with unpopular news. In many countries we find forms of Policy Analysis, Program Evaluation and other kinds of organizational auditing by outside agents, as referred to above; their outcome is second-order feedback which, if used, leads to double-loop learning. All double-loop learning approaches mentioned so far focus very much on the top of the organization. An innovative solution for management control system with double-loop characteristics for use at all levels of the organization is Machin's Expectations Approach (Machin, 1975, 1977, 1978; Machin \& Tai, 1979). It was developed in Great Britain and reflects a British tolerance for ambiguity which will not be as easily accepted in cultures with a stronger need for formal rules. In the expectations approach, each manager defines what he expects from every other manager with whom he interacts in his daily job, and what he believes every other manager expects of him. These expectations are listed and sorted by computer, and compared for every pair of managers. Disagreements are subsequently

${ }^{14}$ Beer $(1975$, p. 497$)$ describes such a system: "The crisis usually arrives when the bosses of the total system perceive the organization as a veritable chaos they can barely influence, while at the same time the individuals running the parts perceive an autocratic regime that ties their hands. The bosses see themselves as uttering genuine policies - mere prescriptions; those at the lower level receive inhibiting rules - genuine proscriptions".

${ }^{15}$ March now differs strongly with Cyert, his co-author of their publication, A Behavioral Theory of the Firm (Cyert \& March, 1963), on the principles on which (U.S.) universities should be managed. Cyert (who has become a University President) has come to defend a highly formalized, centralized objective-setting-planning and budgeting operation, in radical opposition to March (Dill, 1975). 
ironed out. Although this looks like a communications audit, it is a control system as well, because it should reveal ineffectiveness and inefficiency (reflected in non-matching expectations) and allow elimination of these. It should be repeated periodically.

Karl Popper has warned us to beware of systems that promise maximum good to everybody, because these usually turn out to bring maximum evil. He suggests aiming for minimum evil; this is essentially an incrementalist approach, fitting in with Lindblom's (1959) "muddling through" and also defended by Wildavsky (1975). ${ }^{16}$ The "garbage-can" model of organizational choice as described earlier, although not necessarily beautiful, may be the most realistic model of how organizations in fact do or do not learn. Organizations and policies may benefit from incremental improvements to their choice of "garbage-can", rather than from making new and costly Type II errors.

To Luc Wilkin from Belgium, I owe the remark that accountants tend to see "control" as a solution, sociologists as a problem. I believe that to the responsible manager, control is always both a solution and a problem, and he or she will be wise not to mistake the solutions for problems (a Type I error) nor the problems for solutions (a Type II error).

\footnotetext{
${ }^{16}$ Michael (1973) offers a grand design for "Long Range Social Planning" through "Future-Responsive Societal Learning". He takes issue with the "disgruntled incrementalism" of political scientists like Lindblom and Wildavsky. I am afraid his solution is psychologistic (focussing on individual personality change) and therefore institutionally naive, and that a procedure like the one which he proposes would in fact increase rigidity rather than decrease it.
}

\section{BIBLIOGRAPHY}

Abt, C. C., The Evaluation of Social Programs (Beverly Hills, Calif.: Sage Publications, 1976).

Aharoni, Y., Cost Effectiveness, Budgetary Decision Process and Itemization: Some Behavioral Considerations. Working Paper No. 193. Stanford, Calif.: Graduate School of Business, Stanford University, 1971.

Anthony, R. N., Planning and Control Systems: A Framework for Analysis (Boston, Mass.: Division of Research, Graduate School of Business, Harvard University, 1965).

Anthony, R. N., Management Accounting for the Future, Sloan Management Review (1972), pp. $17-34$.

Anthony, R. N. \& Herzlinger, R. E., Management Control in Non-Profit Organizations (Homewood, Ill.: Irwin, 1975).

Argyris, C., Organizational Learning and Management Information Systems, Accounting, Organizations and Society (1977), pp. 113-129.

Ashby, W. R., Introduction to Cybernetics (New York: Wiley, 1956).

Ashby, W. R., Design for a Brain (London: Chapman \& Hall, 1965).

Bariff, M. L. \& Galbraith, J. L., Intra-organizational Power Considerations for Designing Information Systems, Accounting, Organizations and Society (1978), pp. 15-27.

Beer, S., Immanent Forms of Imminent Crisis, Systems and Management Annual (1975), pp. 485-499.

Birnberg, J. G., Frieze, I. H. \& Shields, M. D., The Role of Attribution Theory in Control Systems, Accounting, Organizations and Society (1977), pp. 189-200.

Bower, J. L., Managing the Resource Allocation Process (Homewood, Ill.: Irwin, 1970).

Bruns, W. J. \& Waterhouse, J.H., Budgetary Control and Organization Structure, Journal of Accounting Research (1975), pp. 177-203.

Cantley, M. F., Corporate Planning: A Review of Questions and Answers, Omega (1973), pp. 55-77.

Cantley, M. F., Strategic Control for a U.K. Regional Health Authority - A Conceptual Framework. Research Memorandum, RM-78-54. Laxenburg, Austria: International Institute for Applied Systems Analysis, 1978.

Cheek, L. M., Zero-Base Budgeting Comes of Age: What It Is and What It Takes to Make It Work (New York: Amacom, 1977).

Crozier, M., The Bureaucratic Phenomenon (Chicago: University of Chicago Press, 1964).

Cyert, R. M. \& March, J. G., A Behavioral Theory of the Firm (Englewood Cliffs N.J.: Prentice-Hall, 1963).

den Hertog, J. F., The Role of Information and Control Systems in the Process of Organizational Renewal: Roadblock or Road Bridge?, Accounting, Organizations and Society (1978), pp. 29-45.

Derlien, H. U., Methodische Probleme der empirischen Verwaltungsforschung (Problems of Method in Empirical Research in Public Administration), Schriftenreihe, Nr.9, Bonn: Verein für Verwaltungsreform und Verwaltungsforschung (1978a). 
Derlien, H. U. (1978b) Ursachen und Erfolg von Strukturreformen im Bereich der Bundesregierung unter besonderer Berücksichtigung der wissenschaftlichen Beratung (Causes and Results of Structural Reforms in the Federal Government, With Special Attention to Scientific Counselling), in Verwaltungsreformen und politische Wissenschaft, edited by C. Boehret (Baden-Baden, 1978b), pp. 67-87.

Dill, W. J., When Auld Acquaintance Be Forgot ... From Cyert and March to Cyert vs. March, in R. M. Cyert, ed., in The Management of Nonprofit Organizations: With Emphasis on Universities (Lexington, Mass.: Lexington Books, 1975).

Dirsmith, M. W. \& Jablonsky, S. F., MBO, Political Rationality and Information Inductance, Accounting, Organizations and Society 1979), pp. 39-52.

Draper, F. D. \& Pitsvada, B. T., Zero-Base Budgeting for Public Programs (Washington D.C.: University Press of America, 1979).

Dunbar, R. L. M., Budgeting for Control, Administrative Science Quarterly (1971), pp. 88-96.

Emery, F. E. \& Trist, E. L., The Causal Texture of Organizational Environments, in F. E. Emery, ed., Systems Thinking (Harmondsworth, Middx: Penguin, 1969), pp. 241-257.

Flamholtz, E. G., Toward a Psycho-Technical Systems Paradigm of Organizational Measurement, Decision Science (1979), pp. 71-84.

Hammond, K. R. \& Adelman, L., Science, Values and Human Judgment, in K. R. Hammond, ed., Judgment and Decision in Public Policy Formation (Boulder, Col.: Westview Press, 1978), pp. 119-141.

Hedberg, B. \& Jönsson, S., Designing Semi-confusing Information Systems for Organizations in Changing Environments, Accounting, Organizations and Society (1978), pp. 47-67.

Herzlinger, R. E., Zero-Base Budgeting in the Federal Government: A Case Study, Sloan Management Review (1979), pp. 3-14.

Hofstede, G., The Game of Budget Control (Assen, Neth.: Van Corcum and London: Tavistock, 1967).

Hofstede, G., People and Techniques in Budgeting, in C. B. Tilanus, ed., Quantitative Methods in Budgeting (Leyden, Neth.: Martinus Nijhoff, 1976).

Hofstede, G., Cultural Determinants of the Avoidance of Uncertainty in Organizations. Working Paper 77-18. Brussels: European Institute for Advanced Studies in Management, 1977.

Hofstede, G., The Poverty of Management Control Philosophy, Academy of Management Review (1978), pp. 450-461.

Hofstede, G., Value Systems in Forty Countries: Interpretation, Validation, and Consequences for Theory, in L. H. Eckensberger, W. J. Lonner and Y. H. Poortinga, eds., Cross-Cultural Contributions to Psychology (Lisse, Neth.: Swets \& Zeitlinger, 1979), pp. 389-407.

Hofstede, G., Angola Coffee - Or the Confrontation of an Organization with Changing Values in its Environment, Organization Studies (1980a), pp. 21-40.

Hofstede, G., Culture's Consequences: International Differences in Work-Related Values (Beverly Hills, Calif. and London: Sage Publications, 1980b).

Holling, C. S., Resilience and Stability of Ecological Systems, Annual Review of Ecology and Systematics (1973), pp. 1-23 (also published as Research Report RR-73-3, Laxenburg, Austria: International Institute for Applied Systems Analysis).

Hulshof, A. H., Cont.ol Systems in Non-Profit Organizations. Paper presented at EIASM-IIASA Workshop, Brussels, April, 1979.

Ivancevich, J. K., Changes in Performance by a Management By Objectives Program, Administrative Science Quarterly (1974), pp. 563-577.

Jablonsky, S. F. \& Dirsmith, M. W., The Pattern of PPB Rejection: Something About Organization Structure, Something About PBB, Accounting, Organizations and Society (1978), pp. 215-225.

Landau, M. \& Stout, R., To Manage is Not to Control: Or the Folly of Type II Errors, Public Administration Review (1979), pp. 148-156.

Lindblom, C. E., The Science of Muddling Through, Public Administration Review (1959), pp. 78-88.

Lyden, F. J. \& Miller, E. G., Planning Programming Budgeting: A Systems Approach to Management (2nd Ed. Chicago: Rand McNally, 1972).

Machin, J. L. J., Management Applications of the Expectations Approach: Management Summary Report No. 0077. Peterlee, Durham: IBM UK Scientific Centre, 1975.

Machin, J. L. J., Using the Expectations Approach to Improve Managerial Communications and Organizational Effectiveness, Management Decision (1977), pp. 259-277.

Machin, J. L. J., Management Control Systems: Whence and Whither? Working Paper 33. Durham: Durham University Business School, 1978.

Machin, J. L. J. \& Tai, C. H.S., Senior Managers Audit Their Own' Communication, Journal of Enterprise Management (1979), pp. 75-85.

March, J.G. \& Olsen, J.P., Ambiguity and Choice in Organizations (Bergen, Norway: Universitetsforlaget, 1976).

Michael, D. N., On Learning to Plan and Planning to Learn: The Social Psychology of Changing Toward Future-Responsive Societal Learning (San Francisco: Jossey-Bass, 1973). 
Sarant, P. C., Zero-Base Budgeting in the Public Sector: A Pragmatic Approach (Reading, Mass.: Addison-Wesley, 1978).

Sayles, L., The Many Dimensions of Control, Organizational Dynamics (1972), pp. 21 -31.

Schon, D. A., Beyond the Stable State (London: Temple Smith, 1971).

Selby, C. C., Better Performance from "Nonprofits", Harvard Business Review (1978), pp. 92-98.

Shull, F. A., Delbecq, A. L. \& Cummings, L. L., Organizational Decision Making (New York: McGraw Hill, 1970).

Slovic, P., Judgment, Choice and Societal Risk Taking, in W. R. Hammond, ed., Judgment and Decision in Public Policy Formation (Boulder, Col.: Westview Press, 1978), pp. 98-111.

Stringer, J., Operational Research and Public Policy: Some Thoughts. Paper presented at Second International Research Conference in O.R., Stratford on Avon, April 1976.

Thompson, J. D., Organizations in Action (New York: McGraw Hill, 1967).

Todd, J., Management Control Systems: A Key Link Between Strategy, Structure and Employee Performance, Organizational Dynamics (1977), pp. 65-78.

van de Vall, M. \& Bolas, C., Policy Research as an Agent of Planned Social Intervention: An Evaluation of Methods, Standards, Data, and Analytic Techniques, Sociological Practice (1977), pp. 77-95.

Van Gunsteren, H. R., The Quest for Control: A Critique of the Rational-Central-Rule Approach in Public Affairs (London: Wiley, 1976).

Vayda, A. P.\& McCay, B. J., New Directions in Ecology and Ecological Anthropology, Annual Review of Anthropology (1975), pp. 293-306.

Weick, K. E., Middle Range Theories of Social Systems, Behavioral Science (1974), pp. 357-369.

Wholey, J. S., Zero-Base Budgeting and Program Evaluation (Lexington, Mass.: Lexington Books, 1978).

Wildavsky, A., The Self-Evaluating Organization, Public Administration Review (1972), pp. 509-520.

Wildavsky, A., Budgeting: A Comparative Theory of the Budgetary Process (Boston: Little, Brown \& Co., 1975).

Wildavsky, A., Policy Analysis is What Information Systems Are Not, Accounting, Organizations and Society (1978a), pp. 77-88.

Wildavsky, A., A Budget for All Seasons? Why the Traditional Budget Lasts. Mimeographed preprint for an article in State Audit, a book in honor of I. E. Nebensahl, 1978b. 
